\title{
Effect of Rubber Tyre Granules on Concrete Strength and The Microstructure Characteristics Of Rubberized Concrete
}

\author{
Euniza Jusli, ${ }^{1,}$, Hasanan Md Nor ${ }^{2, b}$, Ramadhansyah Putra Jaya ${ }^{3, c}$ \\ and Zaiton Haron. ${ }^{4, d}$ \\ ${ }^{1,2,3}$ Department of Geothechnics and Transportation, Faculty of Civil Engineering, Universiti \\ Teknologi Malaysia, 81310 Skudai, Johor, Malaysia \\ ${ }^{4}$ Department of Structure and Materials, Faculty of Civil Engineering, Universiti Teknologi \\ Malaysia, 81310 Skudai, Johor, Malaysia \\ aeuniza@live.com, bhasanan@utm.my, 'ramadhansyah@utm.my, 'zaitonharon@utm.my
}

Keywords: strength; microstructure; concrete; waste tyre; rubber

\begin{abstract}
The influence of using rubber tyre granules (RTG) as aggregates on the strength of concrete and microstructure characteristics of rubberized concrete was investigated in this study. Mix proportion of cement: sand: aggregate: superplasticizer; 1:1.5:1.7:0.003 and 0.47 water cement ratio (w/c) was used. The RTG of size $1-4 \mathrm{~mm}$ and $5-8 \mathrm{~mm}$ were used throughout this study. Progressive reduction of compressive strength was observed with the increased of RTG percentage and size. Thermogravimetry and differential thermogravimetric (TGA-DTA) analyses were performed to evaluate the decomposition process of materials heated up to $1000{ }^{\circ} \mathrm{C}$. Less reactions of structure bonds at the range of 2000-3000 $\mathrm{cm}^{-1}$ wavelength were detected in Fourier Transform Infra-Red (FTIR) analysis due to the stability of the structures developed in concrete samples. In general, the main elements in rubberized concrete were calcium, carbon, silica and aluminum. The existence of SBR and carbon black of RTG in the sample can be observed by the presents of a carbon peak in EDX.
\end{abstract}

\section{Introduction}

Nowadays waste tyre rubber has been used in construction industry, onshore and offshore structures, retaining wall, barriers, road pavements and artificial reef to improve fishing [1,2,3]. Using rubber tyre granules (RTG) to replace natural aggregate in concrete production are receiving more attention now since they have been found to generally improve properties of concrete, and in the process, reducing the cost and negative environmental effects [4]. The advantage of using RTG in concrete include increased capacity to absorb energy from impacts [5] and increased deformation and durability [6]. Concrete has a complex structure and believed to have high fire resistant materials [7]. The elasticity, hardness and non-biodegradable properties of RTG may be adopted in order to improve concrete resistance on heat or climate change. The effects of using RTG as aggregate in concrete production were discussed in this paper. The investigation involved a study on concrete strength, morphology of rubberized concrete, thermal and FTIR analysis.

\section{Materials Properties and Experimental Works}

Materials. Ordinary Portland cement (OPC) and rubber tyre granules (RTG) were used in this study. The OPC used are composed of $21.28 \%$ silicon dioxide $\left(\mathrm{SiO}_{2}\right), 5.60 \%$ aliminium oxide $\left(\mathrm{Al}_{2} \mathrm{O}_{3}\right), 3.36 \%$ iron oxide $\left(\mathrm{Fe}_{2} \mathrm{O}_{3}\right), 64.64 \%$ calcium oxide $(\mathrm{CaO}), 2.06 \%$ magnesium oxide $(\mathrm{MgO})$, $2.14 \%$ sulfur trioxide $\left(\mathrm{SO}_{3}\right)$ and $0.05 \%$ total alkalis [8]. Rubber tyre granules were obtained from the mechanical shredding of automobile waste tyre rubber done by Yong Fong Rubber, Malaysia. Two sizes of RTG particles, i.e., $1 \mathrm{~mm}$ to $4 \mathrm{~mm}$, and $5 \mathrm{~mm}$ to $8 \mathrm{~mm}$ were used as partial substitutes of the fine and coarse aggregates, respectively. The RTG used in this study were generally made of $48 \%$ styrene-butadience rubber (SBR), $47 \%$ carbon black, $1.9 \%$ extender oil, $1.1 \%$ zinc oxide, $0.8 \%$, sulfur, $0.7 \%$ accelerator and $0.5 \%$ strearic acid [9]. Crushed granites with a specific gravity 2.50 as coarse aggregate and natural river sand with specific gravity of 1.65 were used in concrete mixture. A Glenium C380 superplasticizer was added to the mixture in order to enhance the workability of concrete. 
Mix proportion and specimens. All concrete specimens were prepared with water to cement ratio $(\mathrm{w} / \mathrm{c})$ of 0.47 . Rubber tyre granules were used to replace natural aggregate at levels of $0 \%$, $10 \%, 20 \%, 30 \%$ and $40 \%$. Mix proportion of cement: sand: aggregate: superplasticizer; 1: 1.5: 1.7: 0.003 was used throughout this investigation. The RTG, OPC, aggregates, water, and superplasticizer were thoroughly mixed in the mixer to form uniform concrete mixture. The mixture was then poured into $100 \times 100 \times 100 \mathrm{~mm}^{3}$ mould and compacted using vibration table for 10 seconds to remove air. The fresh samples were covered with polyethylene sheet for 24 hours before the samples were removed from the mould and cured in water for 28 days.

Compressive Strength Test. The compressive strength of cube was tested at 28 days in accordance with BS EN 12390 Part 3 [10]. The compressive strength was performed using a compression machine with maximum capacity of $3000 \mathrm{kN}$ and $2.50 \mathrm{kN} / \mathrm{s}$ loading rate was applied to the nominal area of the concrete specimen. Each compressive strength and mass loss value represents the average of five samples.

Thermogravimetric Analysis (TGA). The TGA analysis was conducted using a Shimadzu thermal analyzer instrument, model TA-60WS. A total of $25 \mathrm{mg}$ specimens were placed in a platinum pan and heated up to $1000{ }^{\circ} \mathrm{C}$ in a nitrogen-rich atmosphere with a constant heating rate of $10{ }^{\circ} \mathrm{C} / \mathrm{min}$.

Fourier Transform Infra-Red (FTIR). The Perkin Elmer Spectrum 100 FT-IR was used to characterize the samples. The samples were taken from crushed concrete specimen and grinded to obtain powder from before testing. The FTIR analysis was carried out using the potassium bromide $(\mathrm{KBr})$ pellet method ( $1 \mathrm{mg}$ sample per $100 \mathrm{mg} \mathrm{KBr})$ on a spectrometer, with 32 scans per sample collected from 4000 to $650 \mathrm{~cm}^{-1}$ at $4 \mathrm{~cm}^{-1}$ resolution.

Field Emission Scanning Electron Microscope (FESEM). The morphology of concrete sample was characterized using a field emission scanning electron microscope, Hitachi SU8020. Prior to FESEM analysis, coating of samples with platinum was performed. The samples was the placed horizontally on the substrate holder $\left(180^{\circ}\right)$ for surface analysis, and then placed vertically $\left(90^{\circ}\right)$ for a cross-sectional view (thickness). Magnifications of 1000 were used to analyze the microstructure of the samples and energy dispersive X-ray (EDX) was performed at an accelerating voltage of $2 \mathrm{kV}$.

\section{Results and Discussions}

Compressive Strength. Fig. 1 illustrates the results of compressive strength of concrete cube containing RTG with different percentage and sizes. The concrete with $1-4 \mathrm{~mm}$ RTG shows better performance with average strength reduction of $21 \%$ compared to $44 \%$ reduction of strength in concrete with coarser size of RTG. The nature characteristics of rubber of having rough surface results in lack of bonding between cement paste and rubber particle. Compressive load caused early failure on cement paste while RTG behaving like springs delay the widening of the existing cracks. More cracks and fractures were observed due to continuous application of load and results in concrete failure [11].

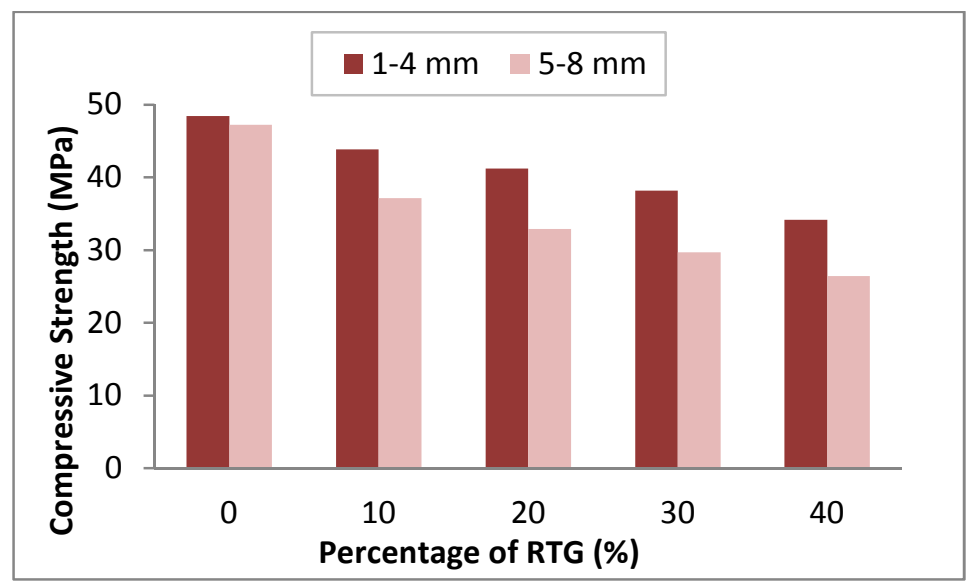

Fig. 1, Compressive strength of concrete containing RTG 
TGA/DTA. According to Fig. 2, the TGA/DTA patterns of the specimen display four endothermic peaks. The first two peaks were located between $50{ }^{\circ} \mathrm{C}$ and $225^{\circ} \mathrm{C}$ is the result of the decomposition of organic materials of RTG and free losses bounded water in concrete. The third endothermic peak at approximately $400{ }^{\circ} \mathrm{C}$ to $500{ }^{\circ} \mathrm{C}$ may related to the decomposition of RTG, including natural rubber and SBR and $\mathrm{Ca}(\mathrm{OH})_{2}$ in concrete [12]. The last endothermic peak, detected between $450{ }^{\circ} \mathrm{C}$ to $1000{ }^{\circ} \mathrm{C}$, is caused by carbon black and zinc oxide of $\mathrm{RTG}$ and decarbonation of calcite.

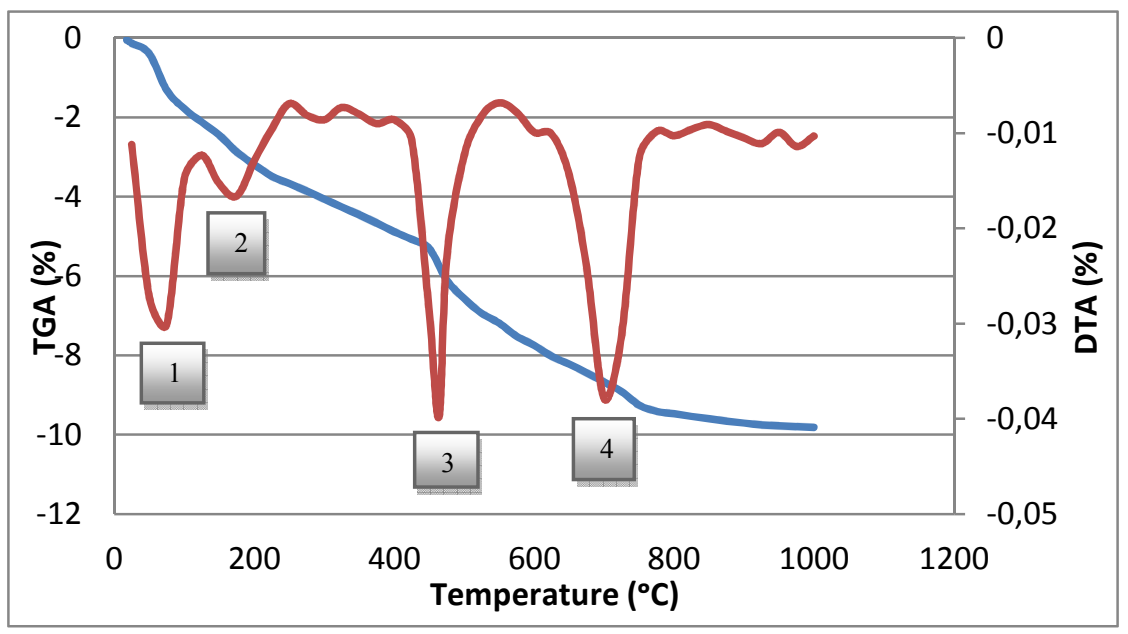

Fig. 2, TGA/DTA curves of concrete containing rubber fired to various temperature regimes

Fourier Transform Infra-Red (FTIR) Analysis. The FTIR spectrum of concrete containing RTG was demonstrated in Fig. 3. Three major bending at approximately 1010, $1450-1650$ and $3500 \mathrm{~cm}^{-1}$ were observed. The main band appears at $1010 \mathrm{~cm}^{-1}$ wavelength indicates the asymmetric starching of C-S-H structure form in concrete sample and crystallization of quartz [13]. At wavelength of $1450-1650 \mathrm{~cm}^{-1}$, it was related to water bound characterized as H-O-H molecule. The structure of water molecule at $3500 \mathrm{~cm}^{-1}$ was known as $\mathrm{O}-\mathrm{H}$ stretching bond. This may related to the hydrated product produced during hydration process of concrete.

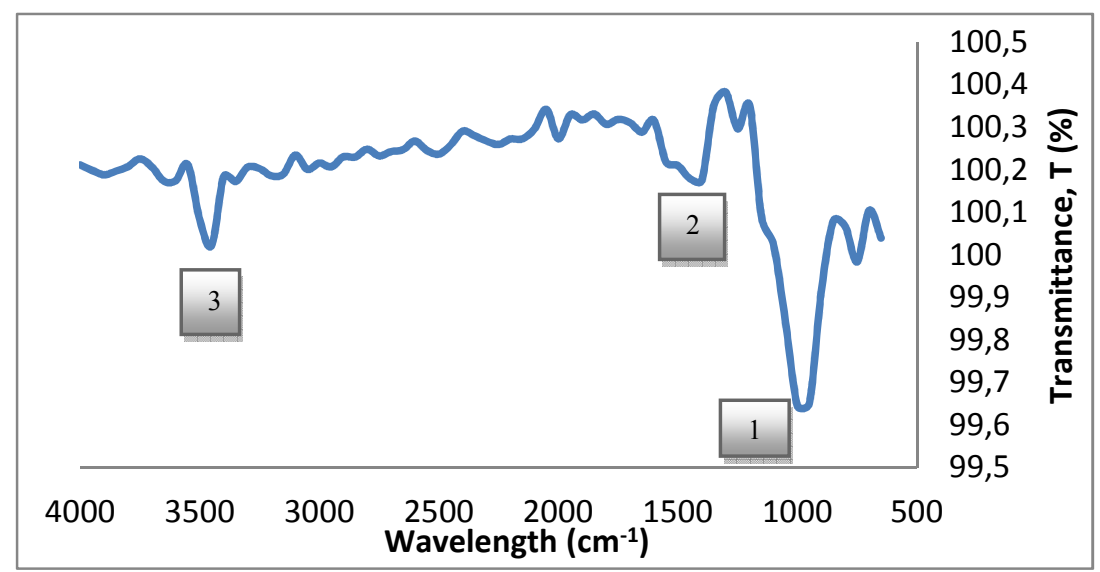

Fig. 3, Fourier transformation infrared spectroscopy of concrete containing RTG

FESEM. The microstructure of the RTG and hardened concrete was observed with the FESEM. Fig. 4 illustrates the existence of hydration products. The morphology of RTG comprised of rectangular-shaped formations with a $7.5 \mu \mathrm{m}$ width and a length of $20 \mu \mathrm{m}$. Pores size ranging between 3.0 to $15.5 \mu \mathrm{m}$ were also observed. In addition, energy dispersive X-ray (EDX) analysis was conducted to determine the existing rubber compounds. The EDX analysis of the rubber tyre granules was illustrated in Fig. 5. The main elements detected were calcium, carbon, silica and aluminum. The presence of SBR and carbon black of RTG in the sample can be observed by the presents of a carbon peak in EDX. 

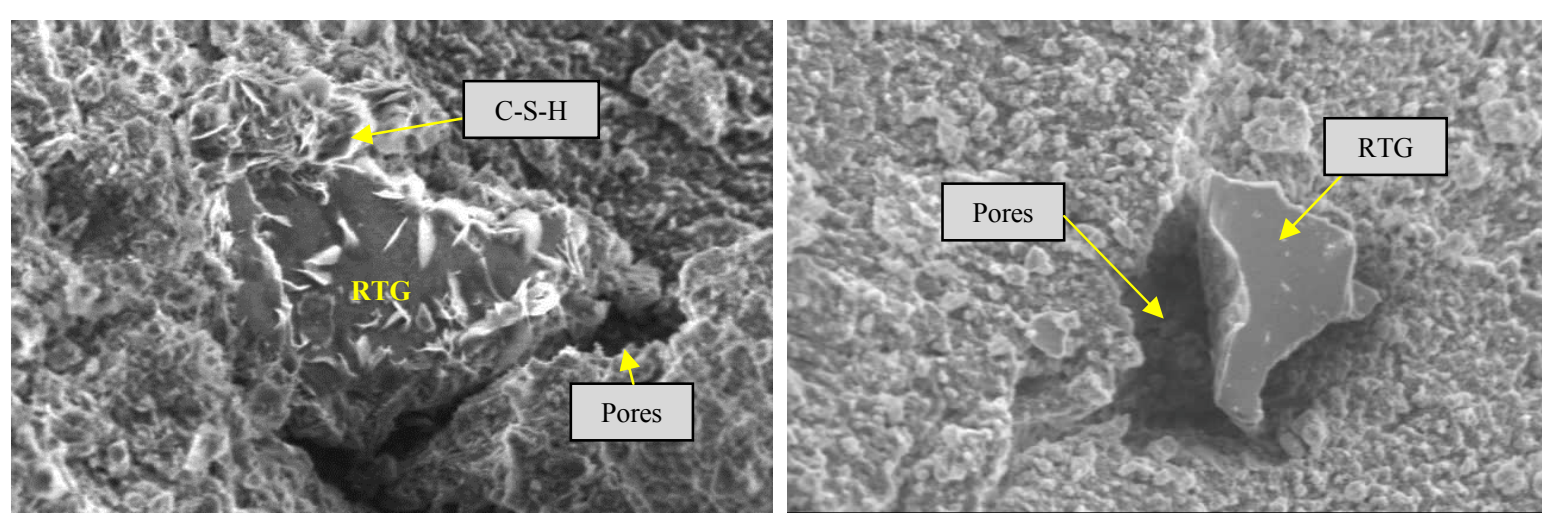

Fig. 4, FESEM of RTG and concrete

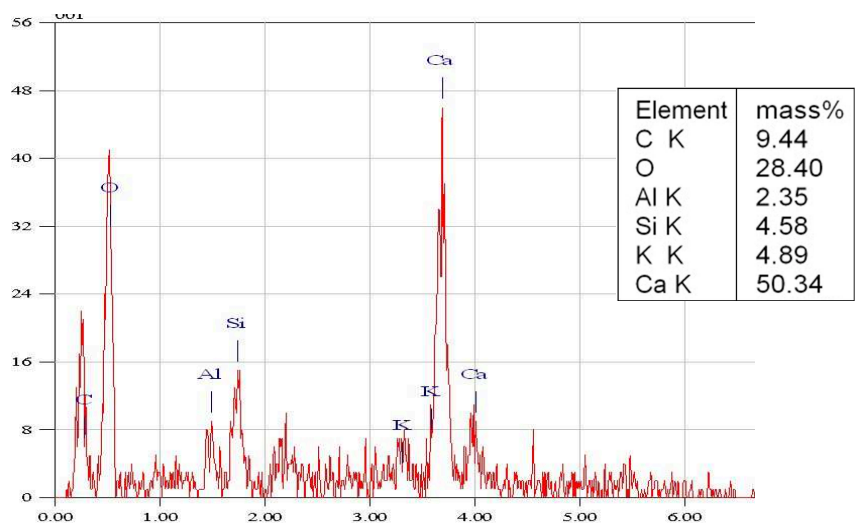

Fig. 5, EDX of concrete containing RTG

\section{Summary}

The following conclusions are derived based on the study of the influence of using rubber tyre granules (RTG) as aggregates on the strength of concrete and microstructure characteristics of rubberized concrete:

1. The concrete with $1-4 \mathrm{~mm}$ of rubber tyre granules shows better performance with average strength reduction of $21 \%$ compared to $44 \%$ reduction of strength in concrete with $5-8 \mathrm{~mm}$ of RTG.

2. Thermal analysis highlighted four major peaks that indicate decompositions of hydration products and rubber tyre materials and completed approximately at $900{ }^{\circ} \mathrm{C}$.

3. The FTIR analysis indicated that less reaction were detected at $2000-3000 \mathrm{~cm}^{-1}$ wavelength due to the stability of structures formed in the rubber samples.

4. The main elements detected in concrete containing RTG were calcium, oxygen, silica and aluminum. The presence of SBR and carbon black of RTG in the sample can be observed by the presents of a carbon peak in EDX.

\section{Acknowledgement}

The authors would like to thank Ministry of Higher Education (MOHE) Malaysia and Universiti Teknologi Malaysia Research grants (RUG 03H43) for their financial support for this study. 


\section{References}

[1] T. C. Ling, H. M. Nor and S. K. Lim, Using recycled waste tyres in concrete paving blocks, Proceeding of the Institution of Civil Engineers (2010) 37-45.

[2] J. Euniza, H. M. Nor, P. J. Ramadhansyah, H. Zaiton, Double Layer Concrete Paving Blocks Using Waste Tyre Rubber as Aggregate Replacement, Appl. Mech. Mater. 554 (2014) 128-132.

[3] J. Euniza, H. M. Nor, P. J. Ramadhansyah, H. Zaiton, Mechanical Properties of Double Layer Rubberized Concrete Paving Blocks, Adv. Mater. Res. 911 (2014b) 463-467.

[4] M. Bravo and J. D. Brito, Concrete made with used tyre aggregate: durability-related performance, J. Cleaner Product. 25(2012) 42-50.

[5] I. B. Topcu and N. Avcular, Collision Behaviours of Rubberized Concrete, Cement and Concrete Res. 27(12) (1997) 1893-1898.

[6] L. Zheng, X. Huo and Y. Yuan, Experimentalinvestigation on dynamic properties of rubberized concrete, Constr. Build. Mater. 22 (5) (2008) 939-947.

[7] L. Basheer, P. A. M. Basheer and A. E. Long, Influence of coarse aggregate on the permeation,durability and the microstructure characteristics of ordinary Portland cement concrete, Constr. and Build. Mater. 19(2005) 682-690.

[8] Information on http://www.tasekcement.com/index/cement_facts/cement_quality.html

[9] J. Euniza, H. M. Nor, P. J. Ramadhansyah, H. Zaiton, Chemical Properties of Waste Tyre Rubber Granules, Adv. Mater. Res. 911 (2014a) 77-81.

[10]BS EN 12390 Part 3:2009, Testing hardened concrete Part 3: Compressive strength test, British Standard.

[11] I. B. Topcu,The properties of rubberized concrete. Cement and Concrete Res. 25(2) (1995) 304-310.

[12]E. V. Bystritskaya, T. V. Monakhova and V. B. Ivanov, TGA application for optimising the accelerated aging conditions and predictions of thermal aging of rubber, Polymer Testing. 32 (2013) 197-201.

[13]A. M. Rashad and S. R. Zeedan, Preliminary study of blended pastes of cement and quartz powder under the effect of elevated temperature, Constr. Build. Mater. 29 (2012) 672-681. 